\title{
Errors in proofreading: Evidence for the use of word shape in word recognition
}

\author{
ANDREW F. MONK and CHARLES HULME \\ University of York, Heslington, York Y01 SDD, England
}

\begin{abstract}
Subjects were given a passage to read for meaning while at the same time checking off any misspellings. Critical words in the text were mutilated by either deleting or substituting letters. In half of these mutilations, an ascender in the word was removed, resulting in a large change in the overall shape of the word. In the first experiment, it was found that mutilations involving the substitution of letters were more likely to be noticed than mutila. tions involving deletions. For both types of mutilation, alterations to word shape were more often noticed than alterations that preserved word shape. When word shape cues were eliminated by using mixed-case stimuli in Experiment 2, the shape effect was abolished. The results are interpreted as evidence for a supraletter feature corresponding to word shape.
\end{abstract}

Since the last century, it has been known that skilled readers may identify words more efficiently than nonwords or individual letters (e.g., Cattell, 1886). Possibly the best known demonstration of such an effect is that by Reicher (1969). Here the subject is presented with a word, nonword, or letter followed by a pattern mask and is given a forced choice between two letters that could have occurred in a specified position. Even when the letters are selected so that in the word condition both would spell words, performance is reliably better in the word than in the nonword or letter conditions. An advantage of words over nonwords is also found in studies of simultaneous matching in which response latency is the dependent measure (Eichelman, 1970). These various "word-superiority effects" (for a review, see Baron, 1978) have often been interpreted as meaning that word recognition involves the use of word shape information rather than simply depending upon the recognition of the individual letters of which the word is composed (e.g., McClelland, 1977). According to such a view, features associated with groups of letters (supraletter features) such as the overall shape of the word may be extracted prior to, or in parallel with, information about its component letters. Information about supraletter features may then facilitate the processing of letter identity information.

A more parsimonious view might be to hold that word recognition depends entirely upon information about the identity of its component letters. Sophisticated guessing models assume that supraletter features are not extracted during word recognition. For example, Massaro (1973, 1975) has argued that many existing demonstrations of word-superiority effects can be accounted for in terms of a failure to control for redundancy operating to facilitate the early stages of visual

The first author's research is supported by a grant from the Medical Research Council. information processing. Letters in words are simply more predictable than letters in nonwords or out of context, and so partial information may be used to correctly identify letters in words when time or information is limited. An alternative explanation for wordsuperiority effects that also does not necessitate the idea of supraletter features is in terms of information loss. Information from mechanisms responsible for word identification may simply be more durable and less susceptible to disruption than information from letter recognition processes (Johnston \& McClelland, 1973, 1980).

A resolution of the possible importance of supraletter features is vital to the development of adequate models of word recognition. The most common form of supraletter feature that has been considered is word shape, which may be defined as the pattern of ascenders and descenders in a lowercase representation of the word. In studies of word-superiority effects, a few attempts have been made to manipulate word shape, with mixed results. If word shape is a supraletter feature, then it will be of no use to nonwords, and hence, destroying word shape should affect word stimuli more than nonword stimuli. Such a manipulation can be achieved by printing alternate letters in uppercase; the results of using these mixed-case stimuli are then compared with the results obtained using all lowercase stimuli. McClelland (1976) found no evidence of the predicted interaction in an experiment in which subjects had to identify letters presented in words as opposed to nonwords. Adams (1979) obtained a similar result using a tachistoscopic recognition paradigm. However, Bruder (1978), using a simultaneous matching task, did obtain such an interaction, although it was not apparent in all her experiments. Bruder claims that her effect depends on word frequency and word length.

There are, however, various sorts of evidence from other experimental tasks that are consistent with readers' 
utilizing information about word shape. Rayner (1975) conducted a series of elegant experiments in which subjects read prose passages presented on a CRT display while their eye movements were monitored. In this situation, alterations to specified words in the text can be made just as the subject is moving his eyes to fixate them. In all cases, the word is presented in its correct form when fixated, but while it is in peripheral vision it can be mutilated in a variety of ways. Substituting letters of the same relative height, which preserves the overall shape of the word, produces less disruption of reading performance, as indicated by fixation duration, than substituting letters of different height, which changes the shape of the word. Rayner and his colleagues have now replicated this effect using a variety of experimental techniques (Ehrlich \& Rayner, 1981; Rayner, 1978; Rayner, McConkie, \& Ehrlich, 1980).

In studies of the above type, changes in word shape are produced by changing letters, and thus, the identity of the word itself is changed. It is possible by typographical manipulations to alter word shape while preserving word and letter identity. Using uppercase print simply removes word shape information, and it has been suggested that this is responsible for the reliable decreases in reading speed found for uppercase material (Tinker, 1965). Using case-alternating script actually distorts the shape of a word, and again, this slows reading down (Fisher, 1975). F. Smith (1969) makes the important point that both these manipulations confound a change in the available discriminable features (shape changes) with a change in familiarity. He ran an experiment that suggests that it is the change in available information that is crucial for the effects of case alternation. By using different-sized type faces, he constructed alternating-case passages that maintain appropriate height information. He found that reading time on such passages was normal, whereas alternating-case passages composed of a single type face were read significantly more slowly than normal text.

These experiments, among others, indicate that changes in word shape do affect recognition, but they may be explicable without recourse to explanations involving word shape or other supraletter features. A simpler explanation in terms of letter-level effects may be possible. When words are mutilated by substituting letters, as in Rayner's experiments, the degree of similarity of the mutilated word to the original is confounded with the degree of similarity of the changed letter to its original. Bouma (1971) has shown that the relative height of letters is an important cue to their identification. Similarly, removing relative height information by using alternating-case texts may have its effect at the letter level.

In an attempt to overcome these problems in demonstrating the importance of word shape, we decided to use a proofreading task in which critical words in the text are mutilated by either deleting or substituting letters. The letter changed might be an ascender, in which case the result was a large change in word shape (so, for example, "latest" becomes "lacest" in the substitution condition or "laest" in the deletion condition). In other cases, when the letter changed was not an ascender or descender, the word shape of the misspelling is reasonably similar to the original word (e.g., "latest" becomes "latect" or "latet"). One might expect changes that result in a large difference in word shape to be more noticeable than those that do not. In the substitution conditions, this could possibly be explained as a letterlevel effect (e.g., changing $t$ to $c$ is more noticeable than changing $s$ to $c$ ), but in the deletion conditions, this is not so. Here there is an equivalent degree of similarity in terms of letter identity information to the original word, as all the letters in the misspelling "belong" in the word. Any effects of shape change found in the deletion conditions cannot be attributed to greater similarity at the letter level.

\section{EXPERIMENT 1}

\section{Method}

Subjects. The subjects in the proofreading experiment were 60 undergraduates. In addition, there were another 17 undergraduates who rated the misspellings for pronounceability.

Materials and Design. The passage used in this experiment was taken from a women's magazine. It was 2,093 words long and dealt with the subject of making stained glass windows. Initially, 60 base words were selected and used to generate 240 misspellings. These misspellings were then given to a group of subjects to rate on a 4-point scale from 4 (very easy to pronounce) to 1 (very difficult). Using these ratings, 40 base words were selected, avoiding base words whose deletion condition misspellings were judged to be very much more pronounceable than their substitution condition misspellings. The result is a set of misspellings balanced for pronounceability (see Table 1).

Each base word had two critical letters, one of each type, which were consonants and which were not the initial or last letter in the word. The first type was an ascender, and the second type was neither an ascender nor a descender. The nonascenders were selected from the set $c, m, n, r, s, v, w$; the ascenders were from the set $b, d, f, h, k, 1, t$ (in 17 of the 40 base words used in the proofreading experiment, the nonascender came before the other critical letter in the word). The base words were selected to contain suitable critical letters, as described above, as well as to satisfy the following constraints: They should be between four and eight letters long, they should not be names, proper nouns, or the first word in a sentence, and they should not be in the same sentence as another base word.

Table 1

Mean Pronounceability Rating (and Standard Deviation) for the Four Different Misspelling Conditions (Maximum 4)

\begin{tabular}{lccccc}
\hline & \multicolumn{3}{c}{ Shape } \\
\cline { 2 - 3 } & \multicolumn{2}{c}{ Same } & & Different \\
\cline { 2 - 3 } \cline { 5 - 6 } & Mean & SD & & Mean & SD \\
\hline Deletion & 3.14 & .47 & & 2.97 & .66 \\
Substitution & 2.87 & .97 & & 2.99 & .59 \\
\hline
\end{tabular}


Deleting the critical letter that was a nonascender resulted in the same-shape deletion condition misspelling. Deleting the critical letter that was an ascender resulted in the differentshape deletion condition misspelling. In the substitution conditions, a letter was chosen from the set c, m, n, r, s, v, w, a, e, o, $u$ and substituted for the critical letter, creating the substitution same- and different-shape conditions in an analogous fashion. The substituted letters were selected to maximize the pronounceability of the misspellings. In no case did any of the misspellings generated constitute an English word. The complete set of misspellings used in the proofreading experiment is presented in the appendix.

Using these materials, four versions of the text were prepared. There were 10 exemplars of each of the four types of misspelling in each version. This assignment of misspellings to versions was random, with the further constraint that each of the 160 misspellings occur only once in the complete set of four versions. Fifteen subjects were assigned to each of four groups at random, and each group had one of the different versions of the passage. The resulting design thus confounds group with the Materials (base word) by Conditions interaction.

Procedure. All the subjects were tested simultaneously in a single session. They were told to read the passage, which was printed with conventional capitalization, for meaning as rapidly as possible and that they would be asked to answer some straightforward comprehension questions at the end. Each subject recorded the time at which he finished reading and then went on to answer six multiple-choice comprehension questions. The proofreading task was introduced as a subsidiary task. Subjects were to circle any misspellings they noticed while they were reading.

\section{Results and Discussion}

The mean reading time was $470 \mathrm{sec}$ which represents an average reading rate of $267 \mathrm{words} / \mathrm{min}$. This is within the normal range of reading speeds and indicates that the addition of the proofreading task has not dramatically changed the way the readers process the text. Similarly, the mean number of comprehension questions answered correctly was 4.1 out of 6 . This indicates that subjects understood the passage adequately, given that each question had three alternative answers, and on the basis of guessing, subjects would be expected to answer two of the six questions correctly.

The detection of misspellings was evaluated in the following way. An analysis of variance was performed on the proportion of hits scored by each subject in each of the misspelling conditions (proportions out of 10 ). Before the analysis was performed, these proportions were transformed using the arcsine transform recommended by Winer (1971), and consequently, the results reported in Table 2 are detransformed mean arcsine proportions. The four misspelling conditions are gener-

Table 2

Detransformed Mean Arcsine Hit Rates for the Four Misspelling Conditions in Experiment 1

\begin{tabular}{lcc}
\multicolumn{2}{c}{ Misspelling Conditions in Experiment 1} \\
\cline { 2 - 3 } & \multicolumn{2}{c}{ Shape } \\
\hline Same & Different \\
\hline Deletion & .554 & .615 \\
Substitution & .759 & .818 \\
\hline
\end{tabular}

ated by two two-level variables: shape (same or different) and type of mutilation (deletion or substitution). Version (represented by groups) is a random materials variable, and so the appropriate error term to evaluate the shape and type of mutilation main effects are the Shape by Version interaction and the Type of Mutilation by Version interaction, respectively. Similarly, the appropriate error term for evaluating the Shape by Type of Mutilation interaction is the Shape by Type of Mutilation by Version interaction.

The most obvious effect in the means presented in Table 2 is type of mutilation. Deletions were considerably less likely to be noticed than substitutions $[F(1,3)$ $=37.841, \mathrm{p}<.01]$. The shape main effect was also significant $[F(1,3)=11.284, p<.05]$, but there was no Shape by Type of Mutilation interaction $[\mathrm{F}(1,3)<1$, n.s.]. It should be noted that the analysis performed takes account of variability across subjects and materials, and because of the small number of degrees of freedom, provides a conservative test of significance. An analysis that takes account of subject variance only, that is, one that takes version to be a fixed effect, gives the same pattern of results [mutilation type: $F(1,56)=93.158$, $p<.01$; shape effect: $F(1,56)=11.695, p<.01$; interaction: $F(1,56)<1$, n.s.].

This finding, that misspellings that maintain word shape are less noticeable than those that do not and that this shape effect is just as strong in the deletion conditions as it is in the substitution conditions, cannot be explained as a letter-level effect. In the deletion conditions, there is no substituted foreign letter that may be more or less confusable with the original letter; all the letters in the deletion condition misspellings belong in the target word. These results demonstrate that, in these circumstances at least, word shape has an effect on reading performance and that the effect is a wordlevel effect; that is to say, word shape has been identified as a supraletter feature.

The finding of a shape effect in proofreading is consistent with the results of Haber and Schindler (1981). Haber and Schindler, however, considered only substitutions, and hence, their results might be explicable in terms of letter-level effects. As mentioned in the introduction, previous studies that have attempted to determine whether word shape is a letter-level or a wordlevel effect have come to differing conclusions. Bruder (1978) has suggested that a possible reason for these discrepancies is that the effects may depend on frequency and word length (see also Healy, 1980).

In the light of these ideas, correlations were computed between the logarithm of the base word's Kuðera and Francis (1967) frequency and the shape effect for each base word. The latter was computed as the difference between the transformed hit rate in the differentshape condition and the transformed hit rate in the sameshape condition. There was no evidence that the shape effect depends on word frequency or length (see Table 3 ). 
Table 3

Correlations With Properties of the Base Words

\begin{tabular}{cccc} 
& $\begin{array}{c}\text { Word } \\
\text { Frequency }\end{array}$ & Length & $\begin{array}{c}\text { Number } \\
\text { Ascenders }\end{array}$ \\
\hline Shape Effect & .04 & \multicolumn{3}{c}{$\begin{array}{c}\text { Deletion Conditions } \\
\text { Shape Effect }\end{array}$} & \multicolumn{2}{c}{ Substitution Conditions } \\
Total Hits & $-.51 *$ & .06 & .05 \\
\hline
\end{tabular}

Note $-N=40$ in all cases. Hit rates were transformed using the arcsine transformation recommended by Winer (1971). Word frequency was transfomed by calculating its logarithm. $* p<.05$.

Also, given that we obtained a shape effect with our stimuli, it is difficult to argue that our stimuli are somehow atypical. Each of the studies mentioned above used a different experimental task, and thus each differed from the others in a number of ways. Our task is different again, and arguably much more realistic than any of the others. It is not clear what the critical differences are between our task, noticing spelling errors while reading for meaning, and these other experimental tasks. It must be admitted, however, that our failure to find an effect of frequency or length on the size of the word shape effect is not conclusive. Our base words include no very high-frequency words such as common function words and only one word shorter than five letters long. It could well be that any effects of these variables are not linear, and it would be desirable in future studies to consider larger ranges of frequency and length (Haber \& Schindler, 1981, present some data relevant to this point).

The other finding, that misspellings created by deleting one letter are noticed less often than misspellings created by substituting one letter, indicates that, unlike word shape, word length is not an important feature of a word. In some ways, this result is not surprising. The visual system is much more effective in detecting patterns such as word shape than detecting absolute quantities such as word length. Furthermore, with proportionally spaced type, it may be difficult to estimate the number of letters in a word from its physical length (our stimuli were not proportionally spaced, but most print is). Nevertheless, this finding has certain implications for models of word recognition, which we will consider later.

Table 3 presents a number of correlations computed between hit rates and properties of the base words used to create misspellings. Correlations were computed with the shape effect, as defined above, and with the total (transformed) hit rate for that base word. It is notable that none of the correlations with the shape effect was significant. Number of ascenders was included to see if the shape of the word prior to mutilation was a critical variable. It is possible that deleting the only letter with an ascender in a word will result in a more dramatic change than deleting one of two or three letters with ascenders. There were 14 one-ascender words, 14 twoascender words, and 12 three-ascender words. Neither the correlations nor a subsequent examination of means showed any effect of this variable. Turning to the correlations with total number of hits, there is a strong negative correlation with frequency. Errors in highfrequency words are harder to spot than errors in lowfrequency words. This result is consistent with a variety of models, such as Morton's (1970) logogen model, in which word frequency has the effect of reducing the criterial evidence necessary for word recognition.

The correlations computed above used the base word as their sampling unit $(\mathrm{N}=40)$. To look at the effects of pronounceability and orthographic regularity, correlations were computed using the misspellings as sampling units. One word, "vocation," has eight letters, and so it was not possible to compute the regularity data with the norms used in the substitution conditions. Hence, $\mathrm{N}=158$ for all the following correlations. Number of hits showed no correlation with pronounceability ( $\mathrm{r}=-.070, \mathrm{n} . \mathrm{s}$.). Likewise, there was no evidence of a correlation with mean single-letter positional frequency ( $\mathrm{r}=-.083$, n.s.) (Mayzner \& Tresselt, 1965), mean digram positional frequency $(r=.012$, n.s. $)$, or mean trigram positional frequency $(\mathrm{r}=.053$, n.s. (Mayzner, Tresselt, \& Wolin, 1965). These correlations provide no evidence for effects of pronounceability or orthographic regularity on this task. While Corcoran (1966) claimed to show effects of pronounciation in a letter-cancellation task, this interpretation has since been rejected (Frith, 1979; Healy, 1976; P. T. Smith \& Groat, 1979). The lack of any effect of orthographic regularity is consistent with the findings from several other studies (Henderson \& Chard, 1980) and should perhaps make us question the adequacy of our present measures of orthographic regularity.

\section{EXPERIMENT 2}

Experiment 1 showed that misspellings that maintain overall word shape are less noticeable than those that do not, even when the misspellings are created by deleting a single letter. This shape effect cannot be explained as due to systematic differences in the pronounceability of the misspellings used or to differences in the orthographic regularity of the misspellings. However, the possibility still exists that there are other differences that are not related to word shape. Nonvisual effects of this kind are not difficult to think of. For example, while we can rule out absolute pronounceability, it is conceivable that there may be systematic differences between same- and different-shape misspellings in the similarity of their sound when pronounced to the sound of their base word. An alternative, quite arbitrary explanation for our results would be to postulate that letters that make up the set of ascenders are somehow given 
more weight in the analysis. Thus, deleting a " $\mathrm{k}$ " or an " 1 ," for example, might be more important than deleting an "m" or an "n."

Experiment 2 was designed to rule out any explanation based on systematic differences in nonvisual properties of the different types of misspelling. In this experiment, the material the subject read was printed in mixed case. The presence of uppercase letters makes overall word shape inappropriate without changing the letters in the word. Thus, if the apparent shape effects observed in Experiment 1 were due to nonvisual properties of the stimuli, they should be unaffected by using mixed-case text. If, on the other hand, as we maintain, the shape effect is due to a supraletter effect due to word shape, the use of mixed-case stimuli will abolish it.

\section{Method}

Subjects. The subjects were 60 school sixth-formers between 17 and 18 years old who had applied to the University of York to study psychology.

Materials and Design. The materials used were identical to those used in Experiment 1, except that they had been processed by a program that randomly changed $50 \%$ of the lowercase letters to uppercase. Random case changes were not used for the misspellings, however. The deletion misspellings were changed so that the remaining critical letter and its immediate neighbors were lowercase and all the remaining letters were uppercase. The substitution misspellings were changed in the same way, but in addition, the substituted letter was also in lowercase. Thus, the base word "latest" becomes "LateT," "LaesT," "LatecT," and "LacesT." When case is changed in this way, the relative height of the critical letters is still apparent, thus giving the maximum chance for letter-level effects to emerge. The procedure in Experiment 2 was exactly the same as that in Experiment 1.

\section{Results and Discussion}

The mean reading time was $670 \mathrm{sec}$, which represents a speed of 187 words/min. As one might expect, this is slower than the reading speeds were in Experiment 1 , but it is still within the bounds of normal reading speeds. Similarly, although the overall number of misspellings noticed was slightly lower than that in Experiment 1, hit rates in the two experiments were clearly comparable. The mean comprehension score was 4.0 out of 6 , which is essentially identical to the score in Experiment 1. There is no reason to believe that using mixed-case text induced a dramatically different reading strategy.

The results for the detection of misspellings are given in Table 4. It is clear that the shape effect was completely abolished by using mixed-case text. There was no shape main effect $[F(1,3)<1$, n.s. $]$ and no Shape by Type of Mutilation interaction $[\mathrm{F}(1,3)<1$, n.s.]. The type of mutilation main effect was still apparent $[F(1,3)=$ 12.364, $\mathrm{p}<.05$ ] ; deletion misspellings were less often noticed than substitution misspellings. Since this effect is not related to word shape, there is no reason for us to expect this effect to be different with mixed-case stimuli.
Table 4

Detransformed Mean Arcsine Hit Rates for the Four Misspelling Conditions in Experiment 2

\begin{tabular}{lcc}
\hline & \multicolumn{2}{c}{ Shape } \\
\cline { 2 - 3 } & Same & Different \\
\hline Deletion & .529 & .517 \\
Substitution & .678 & .680 \\
\hline
\end{tabular}

Since the absence of a shape effect is essentially a null result, a joint analysis was performed on the data from Experiments 1 and 2, in which the factors were experiment, shape, and type of mutilation. A significant Experiment by Shape interaction $[F(1,3)=11.830$, $\mathrm{p}<.05$ ] confirmed that the effects of word shape were significantly reduced by using a mixed-case text, as we had predicted. This abolition of the effect of word shape is a crucial result, since it indicates that the effect of word shape found in Experiment 1 cannot be explained in terms of nonvisual differences between the different types of misspelling.

\section{DISCUSSION}

In Experiment 1, we found that misspellings that alter the shape of a word were more often noticed than those that preserved word shape. This is an effect of word shape that does not seem explicable in terms of letter-level effects. In Experiment 2, we obtained more direct evidence for this idea by distorting word shape through the use of mixed-case passages. When this was done, the effects of word shape observed in Experiment 1 were eliminated. The other effect in our results that is worthy of comment is the very large difference in detection rates between misspellings produced by deleting or substituting letters. We will now consider the implications of these results for theories of word recognition.

As outlined in the introduction, a central theoretical issue in studies of word recognition has been the necessity of postulating the use of supraletter features such as word shape, as opposed to simpler models in which all the information used for word recognition comes from letter recognition processes. Recently, Johnston and McClelland (1980) and McClelland and Rumelhart (1981) have proposed models that predict the occurrence of word-superiority effects without the use of supraletter features. Thus, our demonstration of a supraletter feature corresponding to word shape is incompatible with these models in their current form. To make them compatible, it is necessary to postulate supraletter feature detectors that work in parallel to the subletter feature detectors already postulated by these investigators and which output directly to the word-level processes, that is, bypassing the letter-level processes. As noted earlier, previous studies that have attempted 
to demonstrate a supraletter feature corresponding to word shape have produced conflicting results (Adams, 1979; Bruder, 1978; McClelland, 1976). These studies have used tachistoscopic presentation of single words. and there are many complex differences between them and the present study that make direct comparisons between the various results impossible. It is not at all clear, therefore, why we have found evidence for word shape as a supraletter feature while some previous studies have not. The delineation of conditions under which word shape effects are found is an important issue for further research. However, the present experimental situation is arguably more closely comparable to normal reading than are tachistoscopic studies involving isolated words. It seems reasonable to suppose, therefore, that the word shape effect we have identified is operative during normal reading.

A natural way of explaining the greater frequency with which substitutions are noticed as compared to deletions is in terms of contradictory information. In the case of substitutions, a foreign letter is present, whereas in deletions, it is only that some information normally present in the word is absent. It seems plausible to argue that the system responsible for word recognition should be more tolerant of missing information than of contradictory information that is potentially more informative. A similar effect has been noted by Healy (1981) in detecting substitution errors. She found in a proofreading task that for letters that have the same envelope, readers make more errors when a substituted letter is missing one of the features of the correct letter (as when an "e" is replaced with a "c") than when the substituted letter has an additional feature (as when a " $c$ " is replaced by an "e").

The fact that this effect is still apparent with the mixed-case text used in Experiment 2 suggests that these absent or contradictory elements may be letters or graphemes rather than subletter or supraletter features. In other words, this result means that we can tentatively locate the effect at the point at which a representation of the stimulus as a sequence of letters or candidate letters is matched with a representation of the word as a sequence of letters. This in turn implies a rather poor knowledge of the position of the letters identified, as the deletion condition misspellings have a different length to the base words they are mistaken for. However, it is common to assume that letter identity information is position specific (Bouwhuis \& Bouma, 1979; McClelland \& Rumelhart, 1981). Such a system could not match a stimulus consisting of $n-1$ letters with a word consisting of $n$ letters. Thus, like the word shape effect, this finding poses problems for current models of word recognition.

An alternative way of characterizing word and letter shape is in terms of spatial frequency. The shape of a letter or word corresponds to the low spatial frequency information in its printed form. Thus, if one blurs a word so that only low spatial frequency information is present, what one sees is the overall shape of the word. The visual details correspond to the high spatial frequency information. There are, however, certain serious problems with the idea that letters and words are recognized via their Fourier spectra (see Navon, 1977; also Coffin, 1978).

A less well specified but possibly useful distinction is that made by Broadbent between global and local processes (Broadbent, 1977; Broadbent \& Broadbent, 1977). According to this view, there are two phases in the process of word recognition that interact with each other in a cyclical fashion. The first phase is passive and utilizes information about gross word shape; this phase operates to reduce the range of words to a set that is then tested in the second active phase. The existence of word shape effects is clearly compatible with models of this type. Further, one may speculate that under the conditions of our experiments, syntactic and semantic constraints may lead readers to place a greater reliance on the first phase, especially at points in the text at which those constraints are high. There are data from eye movement studies that are consistent with this possibility. Ehrlich and Rayner (1981) found that subjects had lower probabilities of fixating target words in high-constraint passages and that when they were fixated, they were fixated for less time than in lowconstraint passages.

One other theoretical issue in reading that our results address is the role of phonological coding. In Experiment 1 , a correlation was computed between the pronounceability of misspellings and their detectability, and essentially no relationship was found. This suggests that in the present situation of reading a simple prose passage quickly for meaning, subjects did not utilize a phonological code to any great extent. Clearly, this does not mean that readers never make use of such coding strategies, and indeed, there is evidence from other proofreading tasks that subjects may do so (Cohen, 1980). However, to the extent that our task reflects normal reading, our result suggests that the use of a phonological code is not of great importance to the skilled reader. Our results seem well explained in terms of visual factors, together with the large effect of word frequency that we found, and this is consistent with the claims of Healy (1981) that visual similarity is the main determinant of performance in a proofreading task.

As a final point, we believe that the results of this study, together with others, indicate that proofreading tasks in which the subject is also reading for meaning are a useful additional means for exploring the cognitive processes in fluent reading. They have the advantage of being relatively simple techniques to use. Most important they complement the many experimental tasks that use single words as stimuli by offering the opportunity to manipulate word recognition processes when the words in question are placed in a realistic context. Our 
finding of a clear effect of word shape when such a result has not been obtained in tachistoscopic studies with single-word stimuli suggests that this may make a considerable difference to the conclusions drawn.

\section{REFERENCES}

Adams, M. J. Models of word recognition. Cognitive Psychology, 1979, 11, 133-176.

Baron, J. The word superiority effect: Perceptual learning from reading. In W. K. Estes (Ed.), Handbook of learning and cognitive processes (Vol. 6). Linguistic functions in cognitive theory. Hillsdale, N.J: Erlbaum, 1978.

Bouma, H. Visual recognition of isolated lower case letters. Vision Research, 1971, 11, 459-474.

Bouwhu1s, D., \& Bouma, H. Visual recognition of three letter words as derived from the recognition of the constituent letters. Perception \& Psychophysics, 1979, 25, 12-22.

Broadbent, D. E. The hidden preattentive process. American Psychologist, 1977, 32, 109-118.

Broadbent, D. E., \& Brondbent, M. H. P. General shape and local detail in word perception. In S. Dornic (Ed.), Attention and performance VI. Hillsdale, N.J: Erlbaum, 1977.

Brondenent, D. E., \& Brondenent, M. H. P. Priming and the passive/active model of word recognition. In R. S. Nickerson (Ed.), Attention and performance VIII. Hillsdale, N.J: Erlbaum, 1980 .

Bruder, G. A. Role of visual similarity in the word-superiority effects obtained with the simultaneous matching task. Journal of Experimental Psychology: Human Perception and Performance, 1978, 4, 88-100.

CATtEll, J. The time taken up by cerebral operations. Mind, $1886,11,220-242$.

Cofrin, S. Spectral frequency analysis of block letters does not predict experimental confusions. Perception \& Psychophysics, 1978, 23, 69-74.

CoHEN, G. Reading and searching for spelling errors. In U. Frith (Ed.), Cognitive processes in spelling. London: Academic Press, 1980.

Corcoran, D. W. J. An acoustic factor in letter cancellation. Nature, 1966, 210, 658.

EHRLich, S., \& RAYNER, K. Contextual effects on word perception and eye movements during reading. Journal of Verbal Learning and Verbal Behavior, 1981, 20, 641-655.

Eichelman, W. H. Familiarity effects in the simultaneous matching task. Journal of Experimental Psychology, 1970, 86, 275-282.

Fisher, D. F. Reading and visual search. Memory \& Cognition, $1975,3,188-196$.

Frith, U. Reading by eye and writing by car. In P. A. Kolers, M. Wrolstead, \& H. Bouma (Eds.), Processing of visible language (Vol. 1). New York: Plenum, 1979.

Haber, R. N., \& SchindeER, R. M. Error in proofreading: Evidence for syntactic control of letter processing. Journal of Experimental Psychology: Human Perception and Performance, 1981, 7, 573-579.

Healy, A. F. Detection errors on the word the: Evidence for reading units larger than letters. Journal of Experimental Psychology: Human Perception and Performance, 1976, 2, 235-242.

Healy, A. F. Proofreading errors on the word the: New evidence on reading units. Journal of Experimental Psychology: Human Perception and Performance, 1980, 6, 45-47.

HeaLy, A. F. The effects of visual similarity on proofreading for misspellings. Memory \& Cognition, 1981, 9, 453-460.

Henderson, L., \& Chard, J. The readers implicit knowledge of orthographic structure. In U. Frith (Ed.), Cognitive processes in spelling. London: Academic Press, 1980.

Johnston, J. C., \& MCClemland, J. L. Visual factors in word perception. Perception \& Psychophysics, 1973, 14, 365-370.
Johnston, J. C., \& McClelland, J. L. Experimental tests of a hierarchical model of word identification. Journal of Verbal Learning and Verbal Behavior, 1980, 19, 503-524.

KuCEra, H., \& Francis, W. N. Computational analysis of presentday American English. Providence, R.I: Brown University Press, 1967.

Massaro, D. M. Perception of letters words and nonwords. Journal of Experimental Psychology, 1973, 100, 349-353.

Massaro, D. M. Experimental psychology and information processing. New York: Rand McNally, 1975.

Mayzner, M. S., \& Tresselt, M. E. Tables of single letter and digram counts for various word-length and letter position combinations. Psychonomic Monograph Supplements, 1965, 1, 13-32.

Mayzner, M. S., Tresselt, M. E., \& Wolin, B. R. Tables of trigram frequency counts for various word-length and letterposition combinations. Psychonomic Monograph Supplements, $1965,1,33-78$.

McClelland, J. L. Preliminary letter identification in the perception of words and nonwords. Journal of Experimental Psychology: Human Perception and Performance, 1976, 2, 80-91.

MCCLELLAND, J. L. Letter and configuration information in word identification. Journal of Verbal Learning \& Verbal Behavior, $1977,16,137-150$.

McClelland, J. L., \& Rumelhart, D. An interactive activation model of context effects in letter perception: Part 1 . An account of basic findings. Psychological Review, 1981, 88, 357-407.

Morton, J. A functional model for memory. In D. A. Norman (Ed.), Models for human memory. New York: Academic Press, 1970.

Navon, D. Forest before trees: The precedence of global features in visual perception. Cognitive Psychology, 1977, 9, 353-383.

RAYNER, $K$. The perceptual span and peripheral cues in reading. Cognitive Psychology, 1975, 7, 65-81.

RAYNER, K. Foveal and parafoveal cues in reading. In J. Requin (Ed.), Attention and performance VII. Hillsdale, N.J: Erlbaum, 1978.

Rayner, K., McConkie, G., \& Ehrlich, S. Eye movements and integrating information across fixations. Journal of Experimental Psychology: Human Perception and Performance, 1980, 4, 529-544.

Reicher, G. M. Perceptual recognition as a function of meaningfulness of stimulus material. Journal of Experimental Psychology, 1969, 81, 275-280.

SMITH, F. Familiarity of configuration vs discriminability of features in the visual identification of words. Psychonomic Science, 1969, 14, 261.

Sмith, P. T., \& Gront, A. Spelling patterns, letter cancellation and the processing of text. In P. A. Kolers, M. Wrolstead, \& H. Bouma (Eds.), Processing of visible language (Vol. 1). New York: Plenum, 1979.

Tinker, M. A. Bases for effective reading. Minneapolis: University of Minnesota Press, 1965.

Wine R, B. J. Statistical principles in experimental design. New York: McOraw-Hill, 1971.

\section{APPENDIX \\ BASE WORDS AND MUTILATIONS}

\begin{tabular}{|c|c|c|c|c|}
\hline benches & beches & bences & besches & bencees \\
\hline rarity & raity & rariy & raeity & rariry \\
\hline modern & moden & moern & modean & momern \\
\hline number & nuber & nụmer & nurber & nummer \\
\hline decide & deide & decie & devide & decive \\
\hline strips & stips & srips & stoips & sorips \\
\hline taking & takig & taing & takirg & taving \\
\hline until & util & unil & urtil & unril \\
\hline $\begin{array}{l}\text { hardest } \\
\text { classic }\end{array}$ & $\begin{array}{l}\text { hadest } \\
\text { clasic }\end{array}$ & $\begin{array}{l}\text { harest } \\
\text { cassic }\end{array}$ & $\begin{array}{l}\text { handest } \\
\text { clarsic }\end{array}$ & $\begin{array}{l}\text { harmest } \\
\text { crassic }\end{array}$ \\
\hline
\end{tabular}




$\begin{array}{lllll}\text { created } & \text { ceated } & \text { creaed } & \text { cseated } & \text { creawed } \\ \text { purples } & \text { puples } & \text { purpes } & \text { pumples } & \text { purpmes } \\ \text { depends } & \text { depeds } & \text { depens } & \text { deperds } & \text { depenns } \\ \text { only } & \text { oly } & \text { ony } & \text { osly } & \text { onsy } \\ \text { hands } & \text { hads } & \text { hans } & \text { hamds } & \text { hancs } \\ \text { females } & \text { feales } & \text { femaes } & \text { fevales } & \text { femaves } \\ \text { smiled } & \text { siled } & \text { smied } & \text { sciled } & \text { smiced } \\ \text { think } & \text { thik } & \text { tink } & \text { thirk } & \text { trink } \\ \text { between } & \text { beteen } & \text { beween } & \text { betreen } & \text { berween } \\ \text { feeling } & \text { feelig } & \text { feeing } & \text { feelirg } & \text { feering } \\ \text { latest } & \text { latet } & \text { laest } & \text { latect } & \text { lacest } \\ \text { sucked } & \text { suked } & \text { suced } & \text { surked } & \text { sucred } \\ \text { reckons } & \text { reckos } & \text { recons } & \text { reckoms } & \text { recmons } \\ \text { vocation } & \text { voation } & \text { vocaion } & \text { vosation } & \text { vocasion } \\ \text { install } & \text { intall } & \text { insall } & \text { inntall } & \text { insrall } \\ \text { worked } & \text { woked } & \text { wored } & \text { wonked } & \text { worned }\end{array}$

$\begin{array}{lllll}\text { church } & \text { chuch } & \text { curch } & \text { chunch } & \text { crurch } \\ \text { making } & \text { makig } & \text { maing } & \text { makirg } & \text { maring } \\ \text { fourth } & \text { fouth } & \text { fourh } & \text { founth } & \text { fourch } \\ \text { before } & \text { befoe } & \text { beore } & \text { befome } & \text { bemore } \\ \text { setting } & \text { settig } & \text { seting } & \text { settirg } & \text { serting } \\ \text { alive } & \text { alie } & \text { aive } & \text { alise } & \text { asive } \\ \text { changed } & \text { chaged } & \text { canged } & \text { chaeged } & \text { cranged } \\ \text { craft } & \text { caft } & \text { crat } & \text { coaft } & \text { crast } \\ \text { afford } & \text { affod } & \text { aford } & \text { affond } & \text { anford } \\ \text { awaited } & \text { aaited } & \text { awaied } & \text { amaited } & \text { awaimed } \\ \text { tricky } & \text { triky } & \text { tricy } & \text { trinky } & \text { triccy } \\ \text { plastic } & \text { platic } & \text { pastic } & \text { plantic } & \text { prastic } \\ \text { glowing } & \text { gloing } & \text { gowing } & \text { gloning } & \text { gnowing }\end{array}$

(Received for publication June 9, 1982; revision accepted September 27, 1982.) 